\title{
In Situ Infrared Study of 4,4'-Bipyridine Adsorption on Thin Gold Films
}

\author{
Th. Wandlowski,* K. Ataka, and D. Mayer \\ Institute for Thin Films and Interfaces ISG3, Research Center J ülich, 52425 J ülich, Germany
}

Received J anuary 28, 2002. In Final Form: March 11, 2002

\begin{abstract}
The phase formation of 4,4'-bipyridine (4,4'-BP) and its coadsorption with interfacial water on quasi$\mathrm{Au}(111)$ film el ectrodes $(20 \mathrm{~nm})$ from $0.05 \mathrm{M} \mathrm{KClO}_{4}$ has been studied empl oying in-situ surface enhanced infrared reflection adsorption spectroscopy (SEIRAS). Organic mol ecules form, dependent on the el ectrode potential and in the absence of $F$ aradaic reactions, three monolayers of distincly different orientation. The high coverage adlayer I is composed of perpendicularly oriented 4,4'-BP molecules coordinated with one nitrogen atom to the underlying positively charged electrodes $\left(C_{2 v}\right.$ symmetry). Changing the electrode potential toward negative values causes two first-order phase transitions giving rise to two low-coverage organic adlayers. These transitions are accompanied by an in-plane tilting of the $\mathrm{N}$-coordinated mol ecule. The conclusions on theinterfacial orientation of 4,4'-BP are supported by a comparative analysis of in situ SEIRAS, surface enhanced Raman spectroscopy, and sum frequency generation spectra. SE IRAS spectra also indicate that 4,4'-BP is coadsorbed with water molecules and modifies the interfacial hydrogenbonded network of the later. The nature of these interactions and their consequences for the creation of functionalized adlayers on metal el ectrodes are compared with related N-heterocyclic molecules.
\end{abstract}

\section{Introduction}

The electrochemical adsorption of organic molecules is characterized by (1) interactions with the electrode through image charges and/or substrate-adsorbate coordination, (2) displacement of previously adsorbed solvent molecules and/or electrolyte ions, (3) hydrophobic and hydrophilicinteractions with remaining solvent molecules, and (4) interactions between the adsorbate species. The latter may invol vedispersion and dipole-dipolecoupling, $\pi$-stacking, and/or hydrogen bonding. ${ }^{1}$ Vibrational spectroscopy, such as infrared reflection adsorption spectroscopy (IRAS), ${ }^{2}$ sum frequency generation (SFG) spectroscopy, ${ }^{3}$ surface-enhanced Raman spectroscopy (SERS), ${ }^{4}$ and/or surface-enhanced infrared adsorption spectroscopy $\left(\right.$ SEIRAS) ${ }^{5}$ are powerful techniques for in situ investigations on structure and reactivity aspects of complex interfacial processes under steady-state as well as under dynamic conditions. The combination of SEIRAS and/or SERS with an attenuated total reflection (ATR) configuration provided new insight on theidentity and reactivity of interfacial species, such as water, organic molecules, or ions, under potential controlled conditions at defined interfaces. ${ }^{6-10}$

In 1980 Hartstein et al. reported for the first time that the IR absorption of organic molecules, deposited on thin

* To whom correspondence may be addressed: e-mail, th.wandlowski@fz-juelich.de; fax, 49246161 3462; telephone, 49 2461613907

(1) Guidelli, R. In Adsorption of Organic Molecules; Lipkowski, J ., Ross, P. N., Eds.; VCH: New York, 1992; p 1.

(2) I wasita, T.; Nart, F. C. Prog. Surf. Sci. 1997, 55, 271.

(3) Tadjeddine, A.; Le Rille, A.; Pluchery, O.; Vidal, F.; Zheng, W. Q.; Peremans, A. Phys. Status Solidi A 1999, 175, 89.

(4) Tian, Z. Q.; Ren, B. In Encyclopedia of Analytical Chemistry; Meyers, R. A., Ed.; J. Wiley \& Sons: New York, 2001; p 9162.

(5) Osawa, M. Bull. Chem. Soc. J pn. 1997, 70, 2861.

(6) Ataka, K.; Osawa, M. Langmuir 1998, 14, 951.

(7) Watanabe, M.; Zhu, Y.; Uchida, H. J . Phys. Chem. B 2000, 104, 1762.

(8) Noda, H.; Wan, L. J .; Osawa, M. Phys. Chem. Chem. Phys. 2001 3, 3336.

(9) Bruckenbauer, A.; Otto, A. J . Raman Spectrosc. 1998, 29, 665. 425.

(10) Futamata, M.; Bruckenbauer, A. Chem. Phys. Lett. 2001, 341 gold and silver films, is remarkably enhanced employing the so-called Kretschmann configuration. ${ }^{11}$ Osawa et al. pioneered the application of this techniquefor equilibrium and time-resolved studies at el ectrochemical interfaces. ${ }^{5}$ The surface-enhanced infrared adsorption effect is attributed to (1) a long-range el ectromagnetic mechanism (dominant) that involves the excitation of local surface plasmons within thin films of coinage metals and the polarizability perturbation of the metal by the adsorbate species $^{12}$ and (2) a short-range chemical contribution similar to the charge-transfer mechanism in SERS. ${ }^{13,14}$ The magnitude of the enhanced IR signal, I, depends critically on island structure (size, shape, interparticle spacing, mass thickness) and chemical composition of the metal film. ${ }^{15}$ The surface selection rule of SEIRAS states that only molecular vibrations with dipole changes perpendicular to the surface can be observed, which implies that the exciting electric field is normal to the local surfaces of the metal islands at any point and that s-polarized light does not generate any detectable resonance. ${ }^{5,15}$ Thesurface selection rule is represented by the mathematical expression ${ }^{16}$

$$
\mathrm{I} \sim \Gamma(\mathrm{d} \mu / \mathrm{dQ})^{2}\left|\mathrm{E}^{2}\right| \cos ^{2} \theta \sim \Gamma \cos ^{2} \theta
$$

where $\Gamma$ is the surface concentration and $\theta$ is the angle between the dipole moment derivative of the vibrational mode $(\mathrm{d} \mu / \mathrm{dQ})^{2}$ and the electric filed that excites the molecule $\left|\mathrm{E}^{2}\right|$. Consequently, theobserved spectral features can bedirectly ascribed toa specificinterfacial orientation of the respective adsorbate. The application of ATRSEIRAS experiments at solid/liquid interfaces with well-

(11) Hartstein, A.; Kirtley, J . R.; Tsang, J . C. Phys. Rev. Lett. 1980, 45, 201.

(12) Osawa, M.; Ataka, K.; Yoshi, K.; Nishikawa, Y. Appl. Spectrosc. 1993, 47, 1497.

(13) Siemes, C.; Bruckbauer, A.; Goussev, A.; Otto, A.; Sinther, M.; Pucci, A. J . Raman Spectrosc. 2001, 32, 231.

(14) Merklin, G. T.; Griffith, P. R. Langmuir 1997, 13, 6159

(15) Suetaka, W. Surfacel nfrared and Raman Spectroscopy-Methods and Applications; Plenum Press: New York, 1995.

(16) Cai, W. B.; Wan, L.J .; Noda, H.; Hibino, Y.; Ataka, K.; Osawa, M. Langmuir 1998, 14, 6992. 
defined metal films deposited on highly refractive, IRtransparent prisms has several advantages, in comparison to IRAS studies employing the so-called thin electrolyte film configuration $(1-5 \mu \mathrm{m})$ between the optical window and the working electrode: (1) high and specific surface sensitivity with an enhancement up to ca. 100 times stronger as in conventional IRAS; (2) dominant first layer effect (H el mholtz region) with a short decay length of the enhanced field of 3-4 nm (Gouy region) toward the bulk electrolyte; (3) signals from the interface and the solution background are of comparable magnitude and can be separated by applying the potential differencetactics; (4) no severe limitations dueto mass transport and potential perturbations. 5,17

In this contribution we report an in situ ATR-SEIRAS study in combination with scanning tunneling microscopy (STM) on the phase behavior of 4,4'-bipyridine $\left(4,4^{\prime}-\mathrm{BP}\right)$ and water coadsorbed from neutral aqueous sol ution onto quasi-(111)-oriented thin gold films. The bifunctional nonchelating ligand 4,4'-BP acts as a bridging spacer and coordination unit in 3D and/or 2D supramolecular lattices with novel electric and magnetic properties ${ }^{18,19,20}$ and operates as an electron shuttle in the el ectron transfer of cytochrome c on electrochemical interfaces. ${ }^{21} \mathrm{Michl}$ et al . employed 4,4'-BP with its unique diode-like properties (lone-pair $\sigma$-electrons, $\pi, \pi^{*}$ orbitals) as a basic building block for "conductive" molecular rods to communicate between functional el ements such as "molecular machines" and nanoelectrodes. ${ }^{19,22}$ The torsional angle between the twopyridyl rings ranges, depending on environment (soild, liquid, gas phase) and coordination state, between all planar, $18.5^{\circ}$ and $37.2^{\circ} .{ }^{23-26}$ These values reflect the relative contributions of the $\pi$-electronic interactions of the pyridyl fragments (favorabletocoplanar conformation) and the ortho-bonded interaction of these fragments (favorable to nonplanar structure).

I mpedance (capacitance), voltammetric, and electrore flectance experiments indicate a potential-induced reorientation of 4,4'-BP from flat to tilted or perpendicular on mercury, ${ }^{27}$ gol d, ${ }^{28-31}$ sil ver, ${ }^{32,33}$ and platinum el ectrodes. ${ }^{34}$ Wilde et al. speculate, based on EC-quartz crystal microbalance experiments with $\mathrm{Au}(\mathrm{poly})$, that $4,4^{\prime}-\mathrm{BP}$ is coadsorbed with surface water and anions of the sup-

(17) J ohnson, E.; Avoca, R. J . Phys. Chem. 1995, 99, 9325.

(18) Steel, P. J. Coord. Chem. Rev. 1990, 106, 227

(19) Stoddart, J . F., Ed. Acc. Chem. Res. 2001, 34, $411 \mathrm{ff}$

(20) Chawla, S. K.; Hundal, M. S.; Kaur, J .; Obrai, S. Polyhedron 2001, 20, 2105.

(21) Armstrong, F. A.; Hill, H. A. O.; Walton, N. J . Acc. Chem. Res

1988, 21, 407.

(22) Schwab, R. F.; Levin, M. D.; Michl, J . Chem. Rev. 1999, 99, 1863.

(23) Boag, N. M.; Coward, K. M.; J ones, A. C.; Pemble, M. E.;

Thompson, J. R. Acta Crystallogr., Sect. C 1999, 55, 672.

(24) Spotswood, T.; Tanzer, C. I. Aust. J . Chem. 1967, 20, 1227.

(25) Magutova, Y. S.; Maltseva, L. S.; Kamaer, F. G.; Leontev, B. V.; Mikhamedkhanova, S.; Otrosh, O. S.; Sadykev, A. S. Izv. Akad. Nauk USSR, Ser. Khim. 1973, 7, 1510.

(26) Ould-Moussa, L.; Poizat, O.; Castilla-Ventura, M.; Buntinx, S.; Kassab, E. J . Phys. Chem. 1996, 100, 2072.

(27) Akhmentov, N. K.; Kaganovich, R. I.: Mambetkaziev, E. A. Damaskin, B. B. Electrochimija 1977, 13, 280. Akhmetov, N. K. Kaganovich, R.I.; Damaskin, B. B.; Mambetkaziev, E. A. Electrochimija 1978, 14, 176.

(28) U osaki, K.; Hill, H. O. A. J . Electroanal. Chem. 1981, 122, 321.

(29) Czerwinski, A.; Zamponi, S.; Sobkowski, J .; Marassi, R. Electrochim. Acta 1990, 35, 591.

(30) Sagara, T.; Marakami, H.; Igarashi, S.; Sato, H.; Niki, K. angmuir 1991, 7, 43.

(31) Mayer, D.; Dretschkow, Th.; Ataka, K.; Wandlowski, Th. J Electroanal. Chem., in press.

(32) Cotton, M. T.; Varga, M. Chem. Phys. Lett. 1984, 106, 491.

(33) Liu, T.; Cotton, T. M.; Birke, R. L.; Lombardi, J . R. Langmuir 1989, 5, 406

(34) Chaffins, S. A.; Gui, J . Y.; Khan, B. E.; Liu, C. H.; Salaita, G. N.; Stern, D. A.; Zapien, D. C.; Hubbard, A. Langmuir 1990, 6, 957. porting electrolyte. ${ }^{35,36}$ This idea was supported by a recent in situ ATR study of 4,4'-BP adsorbed under potential control from aqueous sulfuric acid solution onto a thin gold film. ${ }^{37}$ Surface coordination of 4,4'-BP in an end-on configuration was suggested from in situ SERS experiments on Au(poly), ${ }^{38} \mathrm{Ag}$ (poly), ${ }^{32,33,39-41}$ and oneFTIR study on several metal oxide surfaces. ${ }^{42}$ Similar conclusions were also drawn from electron energy loss spectroscopy (EELS) experiments, after transfer of a 4,4'-BP modified $\mathrm{Pt}(111)$ electrode into an ultrahigh vacuum (UHV) system. ${ }^{34}$ Structural details of the steady stateand dynamic phase behavior of up to three ordered 4,4'-BP adlayers on $\mathrm{Au}(111)$ were described by Cunha et al.$^{43}$ and Mayer et al. ${ }^{31}$ in two recent molecular-resolution in situ STM contributions. Umemura ${ }^{44}$ and Pinheiro ${ }^{45}$ et al. reported results of ex situ investigations on the selfassembly of 4,4'-BP on Au(111) from ethanol solution and its coadsorption behavior with phenanthroline and/or merccaptopyrimidine, respectively.

On the basis of our previous STM work we will present in this contribution a comprehensivein situ ATR-SEIRAS study of the vibrational properties of $4,4^{\prime}-\mathrm{BP}$ and coadsorbed water species on quasi-single-crystalline $A u(111)$ film el ectrodes from aqueous electrolytes. The infrared spectra will be compared with SER spectra and results of SFG experiments.

\section{Experimental Section}

IR Spectroscopy. The SEIRAS experiments were carried out in a vertical spectroelectrochemical cell ${ }^{46}$ employing the Kretschmann attenuated total reflection configuration. The working el ectrode, a thin gold film on a highly resistive $(6000 \Omega \mathrm{cm})$ Si hemisphere $(25 \mathrm{~mm}$ diameter), was prepared by el ectron beam evaporation at a base pressure of $2 \times 10^{-7} \mathrm{mbar}$ and a deposition rate of (0.005-0.007) $\mathrm{nm} \mathrm{s}^{-1}$. The mass thickness, $\mathrm{d}_{\mathrm{m}}=20 \mathrm{~nm}$, was measured with a quartz crystal microbalance. The corresponding optical thickness, $\mathrm{d}_{0}$, was estimated by ellipsometry to $23.5 \pm 0.5 \mathrm{~nm}$. The gold film consists of preferentially (111) oriented islands with an average diameter ranging between 20 and $30 \mathrm{~nm}$ (Figure 1). The metal films were electrochemically annealed by cycling the potential in the double layer region with $50 \mathrm{mV} \mathrm{s}{ }^{-1}$. A typical voltammetric response of the resulting film, as for instance obtained after $30 \mathrm{~min}$ in sulfuric acid solution, exhibits well-defined features for the lifting of the $(p \times$ $\sqrt{ } 3$ ) reconstruction $(P 1)$ and the disorder/order phase transition of an $(\sqrt{ } 3 \times \sqrt{ } 7)$ (hydrogen) sulfate overlayer (P2). These observations are indicative of a high area

(35) Wilde, C. P.; Ding, T. J . Electroanal. Chem. 1992, 327, 279

(36) Zheng, X.; Hatton, R. Electrochim. Acta 2000, 45, 3629.

(37) Futamata, M. J . Phys. Chem. B 2001, 105, 6933. Futamata, M. Chem. Phys. Lett. 2000, 332, 421.

(38) Taniguchi, I.; Iseki, M.; Yamaguchi, H. J . Electroanal. Chem. 1985, 186, 29.

(39) Wang, X.; Zhao, B.; Wang, Y.; Wu, Y.; Xu, W.; Fan, X. Mater. Sci. Eng., C 1999, 10, 3.

(40) Miranda, M. Raman Spectrosc. 1996, 27, 435. Miranda, M.; Neto, N.; Sbrana, G. J . Mol. Struct. 1997, 410-411, 205.

(41) Rubim, J . C.; Temperini, M. L. A.; Corio, P.; Sala, O.; Hubert A. H.; Chacon-Villalha, M. E.; Aymonino, P.J .J .Phys. Chem. 1995, 99 345 .

(42) Bagshaw, S. A.; Cooney, R. P. Appl. Spectrosc. 1996, 50, 310

(43) Cunha, F.;Tao, N.J .; Wang, X. W.;j in, Q.; Duong, B.; DeAgnese $\mathrm{J}$.; Langmuir 1996, 12, 6410.

(44) Umemura, K.; Nishida, N.; Hara, M.; Sasabe, H.; Knoll, W. J Electroanal. Chem. 1997, 438, 207.

(45) Pineirho, L. S.; Temperini, M. L. A. Appl. Surf. Sci. 2001, 171 89.

(46) For details see: Wandlowski, Th.; Diesing, D.; Ataka, K. Phys. Chem. Chem. Phys., in preparation. 

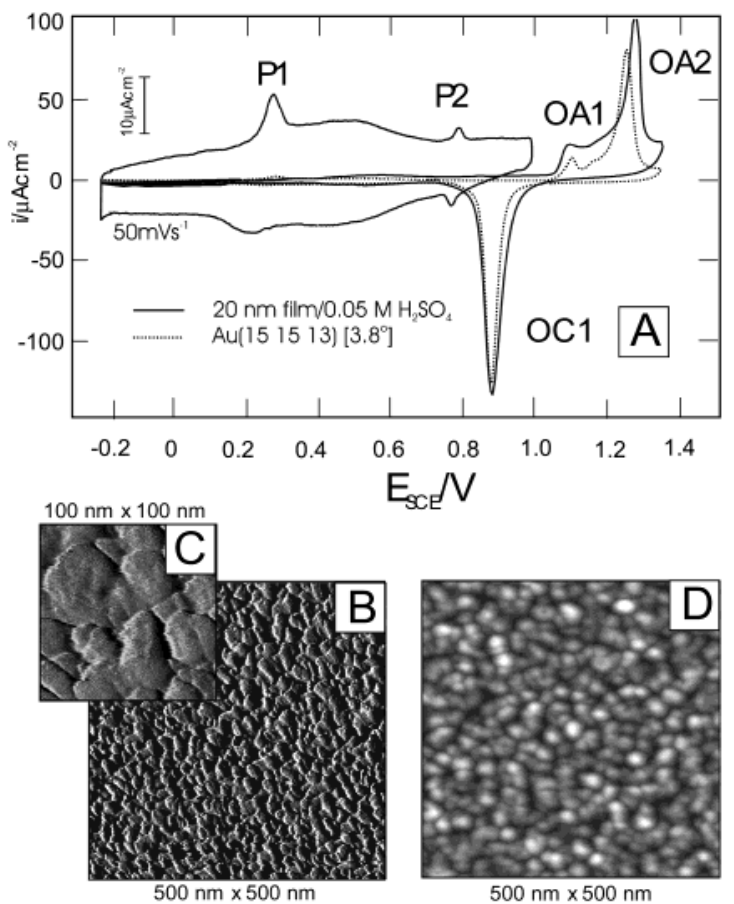

Figure 1. (A) Cyclic voltammograms of quasi-(111) Au (20 nm) film (solid lines) and stepped $A u(1515$ 13) (dotted lines) electrodes in contact with $0.05 \mathrm{M} \mathrm{H}_{2} \mathrm{SO}_{4}$, scan rate $10 \mathrm{mV} \mathrm{s}^{-1}$. The curve showing just the double layer region was recorded with $50 \mathrm{mV} \mathrm{s}^{-1}$ and is plotted in a magnified current scale as indicated. Panels B, C, and D show ex situ STM and AFM images of the Au $(20 \mathrm{~nm})$ film electrodes, as obtained immedeately after evaporation.

percentage of (111)-oriented terrace sites. ${ }^{47}$ The direct comparison of the oxidation/reduction fingerprint region with current vs potential curves measured with stepped single crystals, $A u[n(111) \times(110)]$, yields a rather comparable response of our film with Au[15(111) × (110)] (miscut angle of $3.8^{\circ}$ with respect to an ideal (111)terminated surface), assuming a roughness factor of 2 (Figure 1).

Theinfrared spectra were measured with a Bruker IFS $66 \mathrm{~V} / \mathrm{s}$, choosing a spectral resolution of $4 \mathrm{~cm}^{-1}$. Unpolarized infrared radiation from a globar source was focused onto the el ectrode/el ectrolyte interface by passing through the silicon prism (cf. surface selection rules and ref 46). The incident angle was $70^{\circ}$ referred to the surface normal. The radiation totally reflected at the interface was measured with a liquid nitrogen cooled MCT detector (MCT 316, Colmar Technologies). Typically, 200 interferograms were scanned and coadded into each single beam spectrum $(200 \mathrm{kHz}$ scanning rate of the interferometer). The spectra were plotted in absorbance units defined as $A=-\log \left(I / I_{0}\right)$, where $I$ and $I_{0}$ represent the intensities of the reflected radiation at sample and reference potentials, respectively. The acquisition of spectra was performed either at constant potential or during a sl ow potential sweep with $5 \mathrm{mV} \mathrm{s}^{-1}$. Theel ectrode potential was controlled and synchronized with a HEKA potentiostat PG 310.

Scanning Tunneling Microscopy. The STM and atomic force microscopy (AFM) experiments werecarried out with a Molecular Imaging Pico-SPM. The STM tips were el ectrochemically etched Pt/I r tips (70/30, $0.25 \mathrm{~mm}$ diameter), coated with polyethylene. The in situ experiments were performed with a platinum wire and a gold

(47) Dretschkow, Th.; Wandlowski, Th. Ber. Bunsen-Ges. Phys. Chem. 1997, 101, 749 .

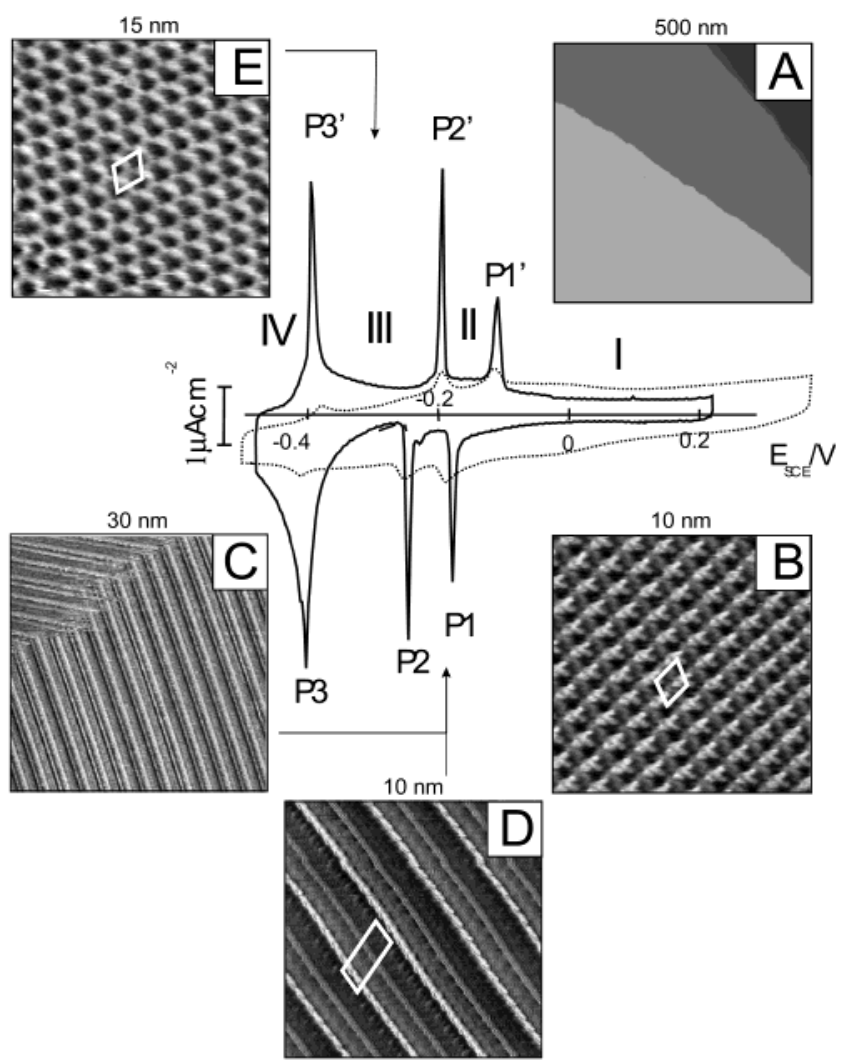

Figure 2. Cyclic voltammogram for $\mathrm{Au}(111)$ (solid line) or $\mathrm{Au}$ (20 nm (111)) (dotted line)/0.05 $\mathrm{M} \mathrm{KClO}_{4}$ in the presence of 3 $\mathrm{mM} 4,4^{\prime}-\mathrm{BP}$, scan rate $10 \mathrm{mV} \mathrm{s}^{-1}$. In situ STM images represent various stages of the potential-dependent adsorption/phase formation processes: (A) electrochemically annealed $\mathrm{Au}(111)$ $(1 \times 1)$ surface at $0.20 \mathrm{~V}$; $(B) 4,4^{\prime}-B P$ adlayer I at $0.17 \mathrm{~V}$; $(C$, D) 4,4'-BP adlayer II at -0.23 and at $-0.21 \mathrm{~V}$; (E) organic adlayer at $-0.32 \mathrm{~V}$. The corresponding unit cells are indicated. The stability regions of the various adlayer phases arelabel ed I -IV.

oxide microelectrodeas counter and referenceelectrodes, respectively. All STM images were recorded at room temperature in constant current mode with tunneling currents ranging between 3 and 200 pA.

Single-Crystal Electrodes and Solutions. The smooth $\mathrm{Au}(111)$ or stepped Au(n n n - 2) = Au[n(111)(110)] electrodes were either single-crystal cylinders (4 mm diameter, $4 \mathrm{~mm}$ height, $\mathrm{EC}$ ) or disks ( $10 \mathrm{~mm}$ diameter and $2 \mathrm{~mm}$ height, STM). Before each measurement the massive gold single crystals were flame annealed in a butane flame at red heat and then cooled in high-purity argon. Contact with theelectrolytewas established under potential control. All potentials in this paper are quoted with respect to the saturated calomel electrode (SCE).

Thesolutions wereprepared with Milli-Q water (18M $\Omega$ $\mathrm{cm}, 3$ ppbTOC), $\mathrm{H}_{2} \mathrm{SO}_{4}$ (suprapure, Merck), $\mathrm{KClO}_{4}$ (Fluka, puriss p.a., twice recrystallized from water). All electrolytes (EC, SEIRAS) were deareated with argon prior to and during each experiment. The measurements were carried out at $20 \pm 0.5^{\circ} \mathrm{C}$

Details of the SERS and SFG will be reported elsewhere. ${ }^{48,49}$

\section{Results and Discussion}

3.1. Electrochemistry and Scanning Tunneling Microscopy. Figure 2 shows typical cyclic voltammo-

(48) Wandlowski, Th.; Lin, W. T.; Huong, Z.; Ren, F. R.; Tian, Z. Q. Chem. Phys. Lett., in preparation.

(49) Wandlowski, Th.; Busson, B.; Vidal, F.; Tadjeddine, A., in preparation. 
grams of $3 \mathrm{mM} 4,4^{\prime}-\mathrm{BP}$ adsorbed from aqueous $0.05 \mathrm{M}$ $\mathrm{KClO}_{4}$ solution $(\mathrm{pH} \sim 5.8)$ onto a perfect $\mathrm{Au}(111)-(1 \times 1)$ single-crystal el ectrode(solid line, Figure 2 ) or ontoa quasi (111) single crystalline $20 \mathrm{~nm}$ thick Au film (dotted line). The latter is supported on a silicon prism. 4,4'-BP molecules assume under these conditions in the bulk electrolyte their unprotonated form $\left(\mathrm{pK}_{\mathrm{a} 1}=3.5 ; \mathrm{pK}_{\mathrm{a} 2}=\right.$ $4.9^{50}$ ). Both sets of data indicate clearly the existence of four different potential regions labeled I-IV, which are separated by distinct charging current peaks P1/P1', P 2/ P2', and P3/P3'. Remarkable is the large hysteresis between the positive and negative potential scans. The experiments with themassivesinglecrystal exhibits nonFaradaic phasetransitions, which arehigher and narrower in comparison with those of the film electrodes. Thecenter peak positions obtained with both types of electrodes are rather similar. These observations correlate with the smaller terracesizeand higher defect density of thelatter (cf. Figure 1). Similar trends werealso reported for order/ disorder phasetransitions in (hydrogen) sulfateadlayers ${ }^{47}$ and physi sorbed uracil films on stepped gold electrodes. ${ }^{51}$

Thestability of rangel is delimited at positive potentials by the competing adsorption of $\mathrm{OH}^{-}$, and the onset of gold oxidation, ${ }^{52}$ and at negativepotentials by thecurrent peaks P1/P1'. Steady-state in situ STM images of adlayer I revealed a periodic array of bright features with characteristic unit cell dimensions of $a=1.10 \mathrm{~nm}\left(\approx 4 \mathrm{a}_{\mathrm{Au}}\right), \mathrm{b}$ $=1.25 \mathrm{~nm}$, and $\alpha=76.5^{\circ}$ (Figure 2B). This result, the anal ysis of high-resolution contrast patterns and domain properties, as well as packing considerations, motivated the hypothetical interpretation of I as a densely packed monolayer of interdigitated, perpendicularly oriented 4,4'BP molecules (six molecules per unit cell, surface concentration $\Gamma_{\mathrm{ml}}=6.9 \times 10^{-10}$ molecules $\mathrm{cm}^{-2}$ ), which are stabilized by $\mathrm{N}$-coordination with the positively charged electrode surface and lateral $\pi$ stacking. 31,43 The highdensity phase transforms upon negative potential excursion into a new striped pattern II (Figure 2C) according to a progressive hole nucleation process combined with surface diffusion-controlled growth. ${ }^{31} \mathrm{High}$-resolution STM images, such as Figure 2D, revealed additional structural details. Assigning tentatively each "elongated" blob to an $\mathrm{N}$-coordinated 4,4'-BP molecule, one may imagine a pattern of four parallel stacking rows. We proposed recently a high-or der commensurate phase with $\mathrm{a}=1.15 \mathrm{~nm}\left(=4 \mathrm{a}_{\mathrm{Au}}\right), \mathrm{b}=2.5 \mathrm{~nm}$, and $\alpha=74^{\circ}$, which contains nine molecules. ${ }^{31}$ The corresponding area per molecule and coverage were estimated as $A_{\| I}=0.29 \mathrm{~nm}^{2}$ and $\Gamma_{\mathrm{mll}}=5.7 \times 10^{-10}$ molecules $\mathrm{cm}^{-2}$.

4,4'-BP molecules assemble intoa third or dered adlayer just after crossing the current peak P2 toward negative potentials. STM experiments at rather low tunneling currents yield a regular rhombohedral arrangement of dark (or bright) spots (F igure2E), which could beresolved at higher tunneling voltages into individual 4,4'-BP molecules arranged in parallel stacking rows. ${ }^{31}$ The suggested unit cell with $a=1.15 \mathrm{~nm}, b=1.3 \mathrm{~nm}$, and $\alpha$ $=71^{\circ}$ contains three molecules with $A_{I I I}=0.47 \mathrm{~nm}^{2}$ and $\Gamma_{\mathrm{mlll}}=3.4 \times 10^{-10} \mathrm{~mol} \mathrm{~cm} \mathrm{~cm}^{-2}$.

The reduction of 4,4'-BP into its anion radical takes place at potentials more negative than P3/P3'.31,38 Capacitance experiments indicate incomplete desorption. Returning the negative-going potential scan before the

(50) Encyclopedia for Chemistry, Basic Part II, 4th ed.; Chemical Society of J apan: Tokyo, 1993; Chapter 10.

(51) Bare, S.; van Krieken, M.; Buess-Herman, C.; Hamelin, A. J . Electroanal. Chem. 1998, 445, 7.

(52) Angerstein-Kozlowska, H.; Conway, B. E.; Hamelin, A.; Stoicoviciu, N.; J . Electroanal. Chem. 1987, 228, 429. onset of 4,4'-BP reduction yields in $-0.500 \mathrm{~V}<\mathrm{E}<0.250$ $\checkmark$ thequasi-steady-statevoltammetricresponseas plotted in F igure 2. Thethreedifferently ordered organicadlayers can be repeatedly created and dissol ved during multiple potential cycles.

Theelectrochemical and STM experimentsindicatethat the transition between the high coverage 4,4'-BP adlayer I toward the phases II and III might be tentatively represented by thesuccessivel oss of parallel stacking rows, reducing the coverage from $6.8 \times 10^{-10} \mathrm{~mol} \mathrm{~cm}^{-2}$ via 5.7 $\times 10^{-10} \mathrm{~mol} \mathrm{~cm}^{-2}$ to $3.4 \times 10^{-10} \mathrm{~mol} \mathrm{~cm}^{-2}$. Unfortunately, the strong variation of the STM contrast pattern of the present system with the applied tunneling conditions, especially the tunneling current, $\mathrm{i}_{\mathrm{T}}$, and the tunneling voltage, $V_{\mathrm{T}}$, as discussed in ref 31 , do not provide an unambiguous understanding of the potential-dependent interfacial orientations of 4,4'-BP and their interaction with solvent (water) molecules and/or ions of the supporting electrolyte. These aspects shall be addressed in the following in situ SEIRAS study.

3.2. Vibrational Spectroscopy, SE IRAS. 3.2.1. Absolute Spectra at Constant Potential and Kinetics of Adlayer F ormation. TheSE IRAS experiment started with a freshly deposited $20 \mathrm{~nm}$ thick gold film as working electrode in contact with $0.1 \mathrm{M}$ aqueous $\mathrm{KClO}_{4}$ solution. After the electrolyte was deoxygenated, the films were electrochemically annealed by cycling the electrode potential with $50 \mathrm{mV} \mathrm{s}^{-1}$ in the double layer region $(-0.60$ $\mathrm{V}<\mathrm{E}<0.60 \mathrm{~V}$ ) until a steady-state response of the electrochemical and spectroscopic signals was obtained (cf. refs 53 and 54).

Due to the incomplete desorption of $4,4^{\prime}-\mathrm{BP}$ and the onset of reduction to form the anion radical at negative potentials, absolute absorbance spectra were measured first in thestability range of phasel at constant potential $(\mathrm{E}=0.200 \mathrm{~V})$. The adsorbate-free $0.1 \mathrm{M} \mathrm{KClO}_{4}$ solution

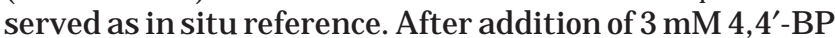
into the stirred electrolyte (argon bubbling) single-beam spectra, obtained from the average of 200 coadded interferograms, were acquired every minute. Positivegoing bands indicate accumulation of the species with respect to the reference, which is represented by the 4,4'BP-free electrolyte. Typical SEIRA spectra of such an experiment areplotted in Figure 3. A steady-statespectral responseis obtained after approximatel y $20 \mathrm{~min}$. Themost prominent positive-going broad bands in the region 3200 $\mathrm{cm}^{-1}<v<3700 \mathrm{~cm}^{-1}$ and around $1656 \pm 3 \mathrm{~cm}^{-1}$ (fwhm $\left.=87 \mathrm{~cm}^{-1}\right)$ are assigned to $\mathrm{OH}$ stretching $\left(v_{\mathrm{OH}}\right)$ and $\mathrm{HOH}$ bending $\left(\delta_{\mathrm{HOH}}\right)$ modes of coadsorbed water species. ${ }^{53}$ The positive sign indicates that the intensity increases with respect to the reference spectrum, e.g., the adsorption of 4,4'-BP increases theamount of oriented, coadsorbed water molecules within the doublelayer region and/or facilitates the formation of strongly hydrogen-bonded interfacial water (Helmholtz, Gouy region). ${ }^{55}$ With the assumption of Gaussian band shapes, the $\mathrm{OH}$ stretching modes could be deconvol uted intothreecontributions, centered at 3605 $\pm 3 \mathrm{~cm}^{-1}$ (fwhm $99 \pm 4 \mathrm{~cm}^{-1}$ ), $3484 \pm 2 \mathrm{~cm}^{-1}$ (fwhm 214 $\left.\pm 4 \mathrm{~cm}^{-1}\right)$, and $3308 \pm 2 \mathrm{~cm}^{-1}\left(\right.$ fwhm $390 \pm 8 \mathrm{~cm}^{-1}$ ), respectively. As a typical example, a set of fitting curves is plotted in Figure 3A. The narrow band around 3605 $\mathrm{cm}^{-1}$ indicates the presence of non-hydrogen bonded $\mathrm{OH},{ }^{55}$ while the broad $v_{\mathrm{OH}}$ bands at 3484 and $3308 \mathrm{~cm}^{-1}$ are assigned to strongly hydrogen-bonded $\mathrm{OH}$ and a Fermi resonance between $v_{\mathrm{OH}}$ and the binary overtone of $\delta_{\mathrm{HOH}} \cdot{ }^{53}$

(53) Ataka, K.; Y otsuyangi, T.; Osawa, M.J . Phys. Chem. 1996, 100, 10664.

(54) Ataka, K.; Osawa, M. J . Electroanal. Chem. 1999, 460, 188.

(55) Thiel, P. A.; Madey, T. E. Surf. Sci. Rep. 1987, 7, 211. 

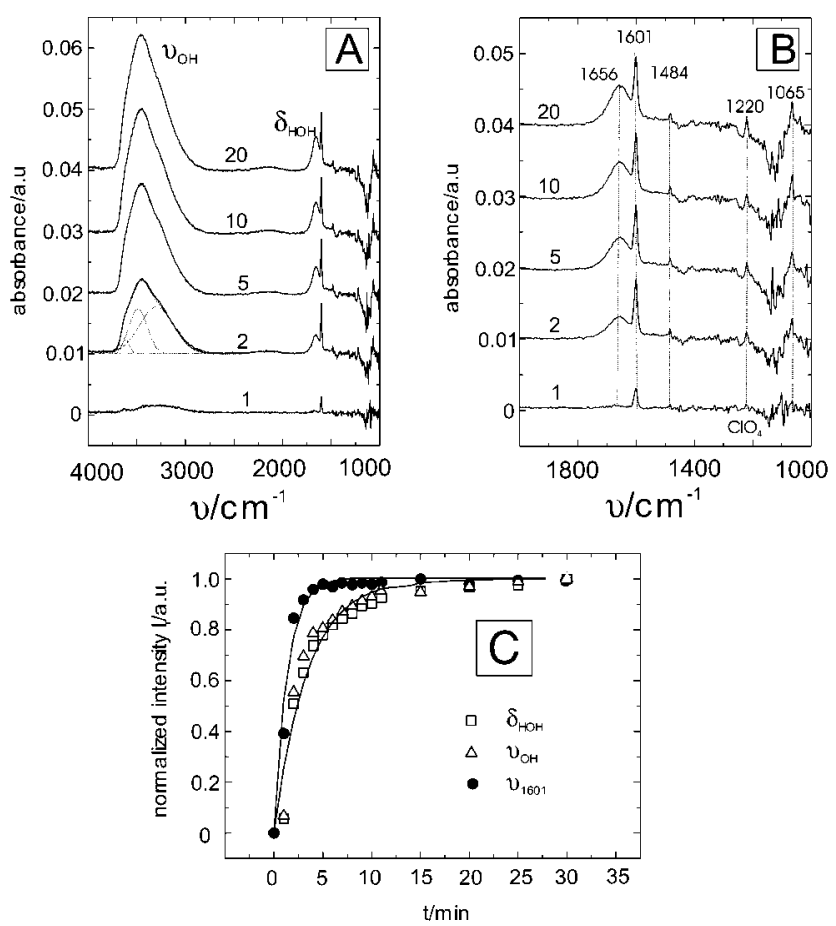

Figure 3. Series of "absolute" SEIRAS spectra of a highly ordered $\mathrm{Au}(111)$ surface in $0.05 \mathrm{M} \mathrm{KClO}_{4}$ as a function of time (indicated in minutes in (A) and (B)) after addition of $3 \mathrm{mM}$ $4,4^{\prime}-\mathrm{BP}$ at $\mathrm{E}=0.20 \mathrm{~V}$. The reference spectrum was measured at $\mathrm{t}=0 \mathrm{~min}$ in the absence of the organic molecule. A typical example of the deconvolution of the $\mathrm{OH}$-stretching region into three Gaussian contributions is also indicated in panel (A). (C) Time dependence of the normalized intensities of $\delta_{\mathrm{HOH}}, v_{\mathrm{OH}}$, and $v_{1601}\left(4,4^{\prime}-\mathrm{BP}\right)$. The solid lines represent fits to eq 1 .

The band center positions and ratios of the integrated intensities of thesethreecontributions do not significantly change with the accumulation time of 4,4'-BP. The later was estimated as 5:33:62. Comparison with the corresponding spectral response of the adsorbate-free electroIyte ${ }^{53}$ indicates that 4,4'-BP modifies the network of hydrogen-bonded interfacial water species. Referring to the previously reported ability of heterocyclic molecules such as cytosine, ${ }^{54}$ pyridine, ${ }^{56} 2,2^{\prime}$-bipyridine, ${ }^{57}$ or pyra$z_{i n e^{58}}$ to replace interfacial water, the present result is rather different and points to a strong hydrophilic character of 4,4'-BP adsorption on Au(111). The spectral features of water at the interface are also different from the spectrum of the bulk electrolyte, which implies that the background absorption of the bulk solution is completely subtracted.

Expansion of the spectrum intothe "finger print" region between 1000 and $2000 \mathrm{~cm}^{-1}$ revealed the bands (Figure 3B), characteristic of adsorbed 4,4'-BP, at 1065 (w), 1220 (w), $1484(\mathrm{w})$, and $1601 \mathrm{~cm}^{-1}(\mathrm{~s})$, which increasein intensity with increasing interfacial coverage of 4,4'-BP. No peak shifts wereobserved, suggesting that molecule-mol ecule and molecule-substrateinteractions areconstant during the adsorption process. These four bands were found at rather similar frequencies in the $\mathrm{KBr}$ spectrum of the moleculeand areattributed toa ring in-planedeformation + ring stretching $\left(v_{18 \mathrm{a}}\right), \mathrm{CH}$ in-plane bending $\left(v_{9 \mathrm{a}}\right), \mathrm{CH}$ in-planebending + ringstretching $\left(\nu_{19 a}\right)$, and a prominent

(56) Cai, W. B.; Wan, L. J .; N oda, H.; Hibino, Y.; Ataka, K.; Osawa, M. Langmuir 1998, 14, 6992.

(57) Noda, H.; Minoka, T.; Wan, L. J .; Osawa, M. J . Electroanal. Chem. 2000, 481, 62.

(58) Cai, W. B.; Amanov, T.; Osawa, M.J . Electroanal. Chem. 2001, $500,147$.

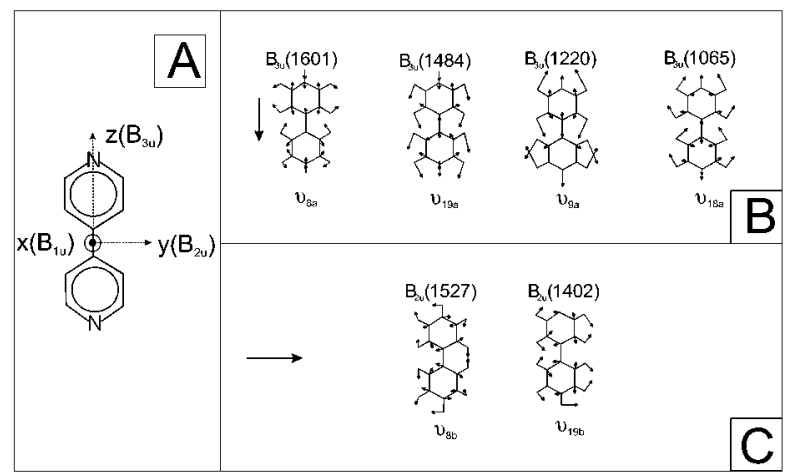

Figure 4. Molecular coordinatesystem (A) and normal modes of experimentally observed in-plane $B_{3 u}$ and $B_{2 u}$ vibrations, with the spectral assignment taken from refs 26,59 , and 60 .

ringstretching mode $\left(v_{8 \mathrm{a}}\right){ }^{26,59,60}$ Thecorresponding Wilson notation is given in parantheses. Referring to the $D_{2 h}$ symmetry of the "free" 4,4'-BP molecules all vibrations observed in the potential region of the adlayer I in 1000 $\mathrm{cm}^{-1}<v<4000 \mathrm{~cm}^{-1}$ represent in-plane $\mathrm{B}_{3 \mathrm{u}}$ modes; no $B_{2 u}$ modes were observed (Figure 4 ). The negative-going (loss) band around $1130 \mathrm{~cm}^{-1}$ is attributed to the replacement of interfacial $\mathrm{ClO}_{4}^{-}$ions. ${ }^{53}$ Thespectral range below $1000 \mathrm{~cm}^{-1}$ could not be analyzed due to the strong absorption of the silicon prism.

Finally we notethat similar observations were madeat any other potentials within the stability range of region I.

The time dependence of the normalized (with the corresponding steady-state response at $\mathrm{t}=30 \mathrm{~min}, \mathrm{E}=$ $0.200 \mathrm{~V}$, as reference), integrated intensities of $v_{1601}$, the most intense vibrational mode of adsorbed 4,4'-BP, and the two water features, $v_{\mathrm{OH}}$ and $\delta_{\mathrm{HOH}}$, is plotted in Figure 3C. $v_{1601}$, as a typical representative of the observed $\mathrm{B}_{34}$ modes of 4,4'-BP reaches saturation after $5 \mathrm{~min}$, while the establishment of the steady-state response of both interfacial water modes, which exhibit rather identical timedependencies, requires approximatel y $20 \mathrm{~min}$. These spectroscopically obtained correlations between relative intensity $I_{r}$ and timet can be represented by a first-order kinetic equation

$$
\mathrm{I}_{\mathrm{r}}=1-\exp (-\mathrm{kt})
$$

with $\mathrm{k}$ as an apparent rate constant. Curve fitting of eq 1 to the experimental transients (solid line in Figure 3C) yields $\mathrm{k}\left(v_{1601}\right)=0.73 \pm 0.03 \mathrm{~min}^{-1}$, and $\mathrm{k}\left(v_{\mathrm{OH}}, \delta_{\mathrm{HOH}}\right)=0.30$ $\pm 0.02 \mathrm{~min}^{-1}$.

These results indicate that the formation of the high coverage 4,4'-BP adlayer (with referenceto theadsorbate free base electrolyte, cf. ref 31) is accompani ed by major, and obviously even slower ordering of interfacial water molecules within the Helmholtz and Gouy regions, both of which are probed. The penetration depth of SEIRA in our configuration does not access further contributions from the bulk electrolyte. ${ }^{5}$

3.2.2. Potential Dependence of 4,4'-BP Adsorption on Au(20nm-111). After a steady-statespectral response was reached in region I at $0.200 \mathrm{~V}$, the potential was slowly scanned with $5 \mathrm{mV} \mathrm{s}^{-1}$ toward $-0.500 \mathrm{~V}$ (limit of the nonFaraday adsorption range of 4,4'-BP 31,43 ) and then back to $0.200 \mathrm{~V}$. The "relative" in situ SEIRA spectra were recorded simultaneously, choosing thesteady-statesingle beam spectrum of the high coverage $4,4^{\prime}-\mathrm{BP}$ phase $\mathrm{l}$ at

(59) Kihara, H.; Gondo, Y. J . Raman Spectrosc. 1986, 17, 263.

(60) Topacli, A.; Akyuz, S. Spectrochim. Acta, A 1995, 51, 633. 

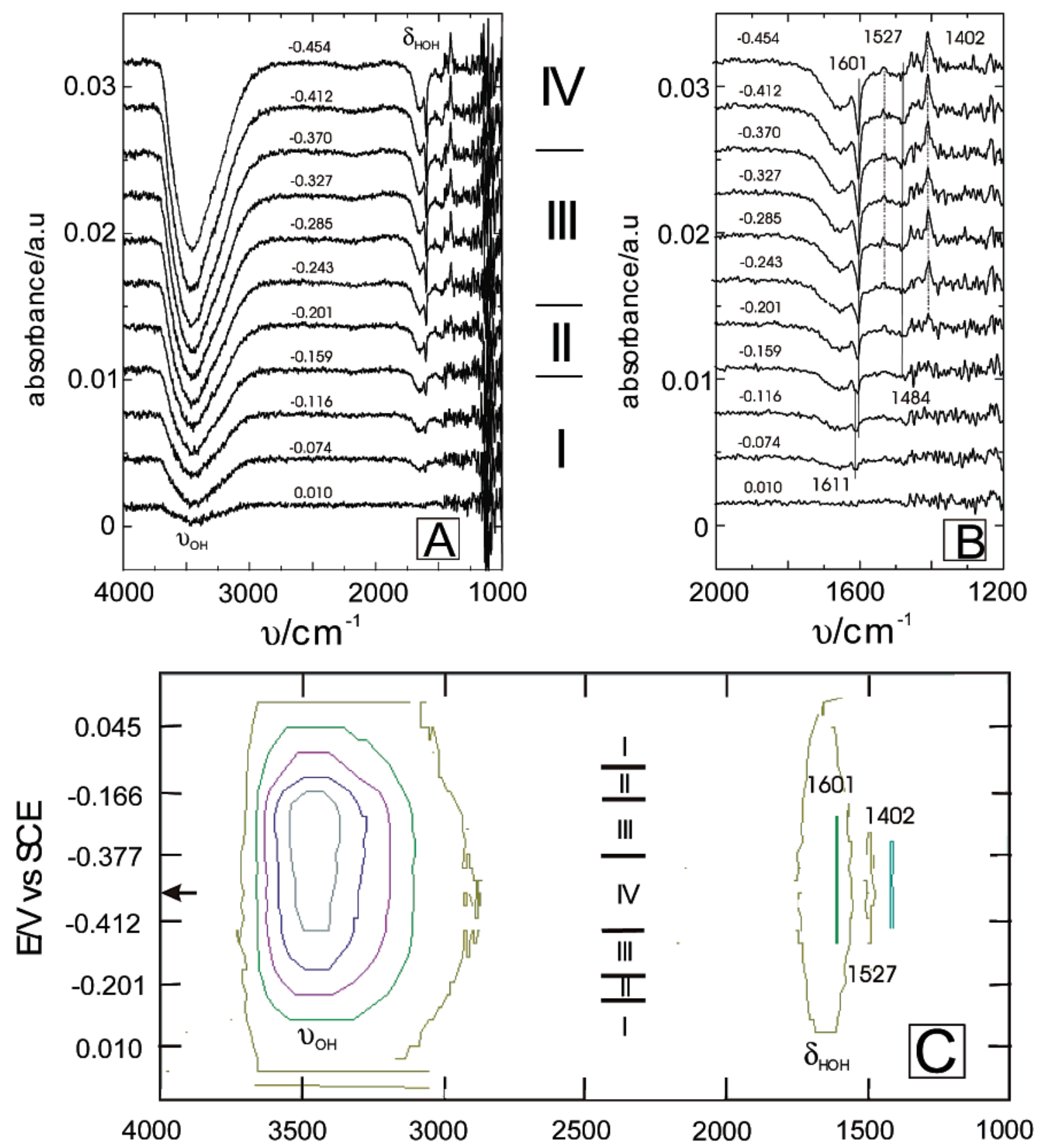

$v / \mathrm{cm}^{-1}$

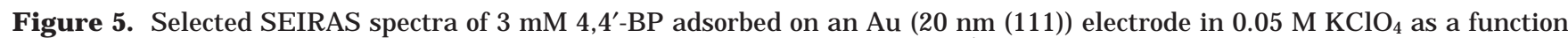
of potential, measured simultaneously with a slow scan voltammogram ( $5 \mathrm{mV} \mathrm{s}^{-1}$, negative potential sweep): (A) overview spectra; (B) zoom-out of the low-frequency range; (C) contour plot. 200 single scans are averaged within each potential interval of $42 \mathrm{mV}$. The reference spectrum was measured at $0.20 \mathrm{~V}$ (phase I).

$0.200 \mathrm{~V}$ as reference. The IR spectra were acquired sequentially at every $42 \mathrm{mV}$, by averaging of 200 individual interferograms. Parts A and B of Figure 5 illustratetypical sets of selected relativespectra as obtained during a sweep toward negative potentials. (Wenotethat downward bands represent loss features with respect tothereferencestate. ${ }^{5}$ ) The contour plot in Figure 5C represents the spectral response of one complete voltammetric cycle. Clearly developed and monotonically growing loss features of interfacial water occur in the $\mathrm{OH}$-stretching $\left(3200 \mathrm{~cm}^{-1}\right.$ $\left.<v<3700 \mathrm{~cm}^{-1}\right)$ and the $\mathrm{HOH}$-bending $\left(1656 \mathrm{~cm}^{-1}\right.$ shifts toward $1646 \mathrm{~cm}^{-1}$ ) regions as well as for the $B_{3 u}$ modes of 4,4'-BP around 1601 (s) and $1484 \mathrm{~cm}^{-1}$ (w) with increasing negative potentials (F igure 5 ). The potential- dependent integral loss intensities of $v_{\mathrm{OH}}, v_{\mathrm{HOH}}$, and $v_{1601}$ are plotted in Figure 6A.

Careful inspection of the potential evolution of the prominent stretching modereveals that upon approaching the voltammetrically determined transition potential P1, an initially splitted double band with centered positions at 1611 and $1601 \mathrm{~cm}^{-1}$ develops. After passing P 1, only the loss feature around $1601 \mathrm{~cm}^{-1}$ increases further in regions II, III, and IV (Figure 5B). A similar splitting of other $\mathrm{B}_{3 \mathrm{u}}$ loss bands could not be detected because of the rather poor signal-to-noise ratio for $v_{1484}$ and the other two $B_{34}$ bands below $1250 \mathrm{~cm}^{-1}$. Nevertheless, this observation may indicate site-specific desorption and/or structural changes within thehigh coverage 4,4'-BP phase. 


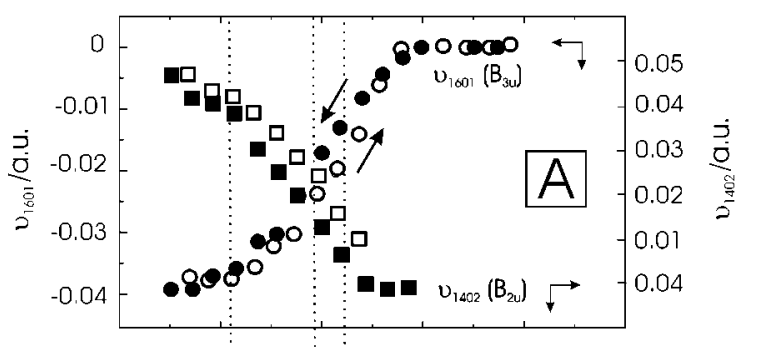

IV $\quad$ III
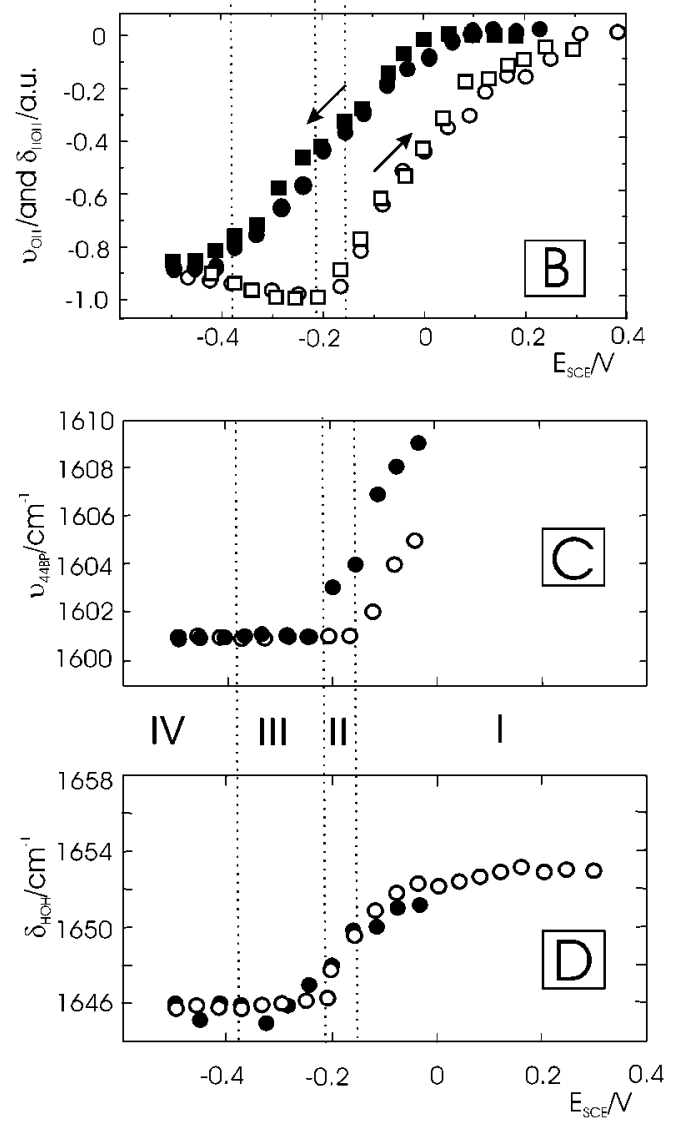

Figure 6. Potential dependence( $A$ ) of theintegrated intensities of the $v_{1601}\left(\mathrm{~B}_{3 u} ; O, \mathbf{O}\right)$ and $v_{1402}\left(\mathrm{~B}_{24} ; \square, \mathbf{\square}\right)$ and $(\mathrm{B})$ of the normalized interfacial water vibrations $v_{\mathrm{OH}}(\bigcirc, \bullet), \delta_{\mathrm{HOH}}(\square, \boldsymbol{\square})$. (C), (D) potential dependence of the band positions of $v_{44 \mathrm{BP}}$ and $\delta_{\mathrm{HOH}}$. The open (filled) symbols represent data aquired during a positive (negative) potential scan.

Similar arguments were recently discussed for pyridine. Hoon-Koshla et al. pointed out that the in-plane ring deformation mode of $\mathrm{N}$-bonded pyridine on $\mathrm{Au}(111)$ splits into a small band at $\sim 1599 \mathrm{~cm}^{-1}$ associated to defect sites, and a main band at $1593 \mathrm{~cm}^{-1}$ (lower wavenumbers!) representing pyridine on (111) terraces. ${ }^{61}$

Simultaneously and correlated to the loss features of interfacial water and of $\mathrm{B}_{3 u} 4,4$ '-BP modes, twonew bands start to grow (positive!) at $v \sim 1402 \mathrm{~cm}^{-1}$, and a weaker feature at $1527 \mathrm{~cm}^{-1}$ (Figure 5). Both could be assigned to in-plane $B_{2 u}$ modes of adsorbed 4, 4'-BP, specifically to thein-plane bending + ring stretching mode $\left(v_{19 b}, \sim 1402\right.$ $\left.\mathrm{cm}^{-1}\right)$ and thering stretching mode $\left(v_{8 b}, \sim 1527 \mathrm{~cm}^{-1}\right){ }^{26,59,60}$ The peak positions are independent of the electrode potential.

These structural changes of adsorbed 4,4'-BP and coadsorbed water arereproducibleduring multiplecycling.

(61) Hoon-Koshla, M.; Fawcett, W. R.; Cheng, A.; Lipkowski, J .; Pettinger, B. Electrochim. Acta 1999, 45, 611.
Changing the direction of theslow potential scan (negative as illustrated in Figure 5, positive not shown) causes a significant hysteresis in the evolution of the respective vibrational modes. Figure 6 illustrates, as a summary of these observations, the potential dependence of the integrated intensities of the two most intense modes of adsorbed 4,4'-BP, $v_{1601}\left(\mathrm{~B}_{3 \mathrm{u}}\right), v_{1402}\left(\mathrm{~B}_{2 \mathrm{u}}\right)$, and of interfacial water, $v_{\mathrm{OH}}$ and $\delta_{\mathrm{HOH}}$. The positi on of the $B_{3 u}$ mode does not change with potential in $-0.600 \mathrm{~V}<\mathrm{E}<-0.500 \mathrm{~V}$, except of the already described satellite feature at $1611 \mathrm{~cm}^{-1}$ around P1. During the negative-going potential scan, the integrated intensity of the $v_{1601}$ loss band $\left(\mathrm{B}_{34}\right)$ decreases initially rather moderately (still in region I), followed by a steep decrease at $\mathrm{E}<-0.100 \mathrm{~V}$ (voltammetric peak $\mathrm{P} 1$, $\mathrm{I} \rightarrow \mathrm{II}$ ), which slows somewhat down at $\mathrm{E}<-0.250 \mathrm{~V}$ (II $\rightarrow$ III) until it levels off at $E<-0.400 \mathrm{~V}$ (P3, region IV). The subsequent positive-going scan is represented by an initial small slope, which increases in twoslightly separate steps at $\mathrm{E}>-0.400 \mathrm{~V}\left(\mathrm{P3}^{\prime}, \mathrm{IV} \rightarrow \mathrm{III}\right)$ and at $\mathrm{E}>-0.220$ $\mathrm{V}\left(\sim \mathrm{P} 2^{\prime}, \mathrm{III} \rightarrow \mathrm{II}\right)$ until the slope levels off at $\mathrm{E}>0.050$ $\mathrm{V}\left(\sim \mathrm{P} 1^{\prime}, \mathrm{II} \rightarrow \mathrm{I}\right)$. The hysteresis of approximately $50 \mathrm{mV}$ between the forward and backward potential scans and thechanges in slope of theloss-intensity vs potential plots correlate nicely with peak position and hysteresis of the corresponding voltammetric response (Figure 2). Similar correlations were found for the $v_{1402}$ gain mode $\left(\mathrm{B}_{2 \mathrm{u}}\right)$. The negative potential scan exhibits a steep increase of the integrated intensity in region $\mathrm{II}(\mathrm{E}<-0.100 \mathrm{~V}, \mathrm{I} \rightarrow \mathrm{II})$, a moderate change in region III until the change levels off in region IV at $\mathrm{E}<-0.400 \mathrm{~V}(\mathrm{III} \rightarrow \mathrm{IV})$. The potential dependencies of theintegrated intensities of $v_{\mathrm{OH}}$ and $\delta_{\mathrm{HOH}}$ are identical (normalized representation in Figure 6B) and reflect changes in the four stability regions of adsorbed 4,4'-BP, and around the various phasetransitions, but do not strictly correlate with the exact positions predicted from the voltammetric experiments. Remarkable is the hysteresis of approximatel y $0.200 \mathrm{~V}$ between theresponses of thenegativeand positive potential scans (e.g., four times that of the 4, 4'-BP modes). The water relaxation appears to be more pronounced within the IR-probed interfacial region than the sole rearrangement of the 4,4'-BP molecules. Interestingly, thelatter seems to dominatethe charging current-potential or time response (voltammetry, chronoamperometry). Deconvol ution of the complex $v_{\mathrm{OH}}$ stretching mode, with the assumption of Gaussian line shapes, reveals three components centered at 3600 \pm 7 (fwhm $\left.\sim 110 \pm 10 \mathrm{~cm}^{-1}\right), 3484 \pm 5$ (fwhm $\sim 210 \pm$ $\left.7 \mathrm{~cm}^{-1}\right)$, and $3315 \pm 20 \mathrm{~cm}^{-1}\left(\mathrm{fwhm} \sim 330-370 \mathrm{~cm}^{-1}\right)$, rather independent of theapplied el ectrode potential, and with relative contributions of 5:35:60. These results are similar to those reported previously for the absolute spectra in region I. Thecenter position of the $\delta_{\mathrm{HOH}}$ bending mode shifts with potential from $1654 \pm 1 \mathrm{~cm}^{-1}$ in region I $(\mathrm{E}>-0.100 \mathrm{~V})$ to lower wavenumbers, $1646 \pm 2 \mathrm{~cm}^{-1}$ in region IV (Figure 6D). This trend indicates a slight but significant decrease of interfacial hydrogen bonding. Compared with the perchlorate containing electrolyte in theabsence of 4,4'-BP, the position of the $\delta_{\mathrm{HOH}}$ modeoccurs at negative potential s at higher wavenumbers $\left(1646 \mathrm{~cm}^{-1}\right.$ instead of $1612 \mathrm{~cm}^{-153}$ ), which clearly represents the promotion of hydrogen bonding in the presence of 4,4 BP.

No change of the baseline or background reflectivity of the electrode was observed within the potential range of an ideal polarizable $\mathrm{Au}(20 \mathrm{~nm}) / 0.1 \mathrm{M} \mathrm{KClO}_{4}+3 \mathrm{mM} 4,4^{\prime}-$ $\mathrm{BP}$ interface. The reflectance change in the IR region represents predominantly the optical properties of the metal substrate. In consequence, one may conclude that 


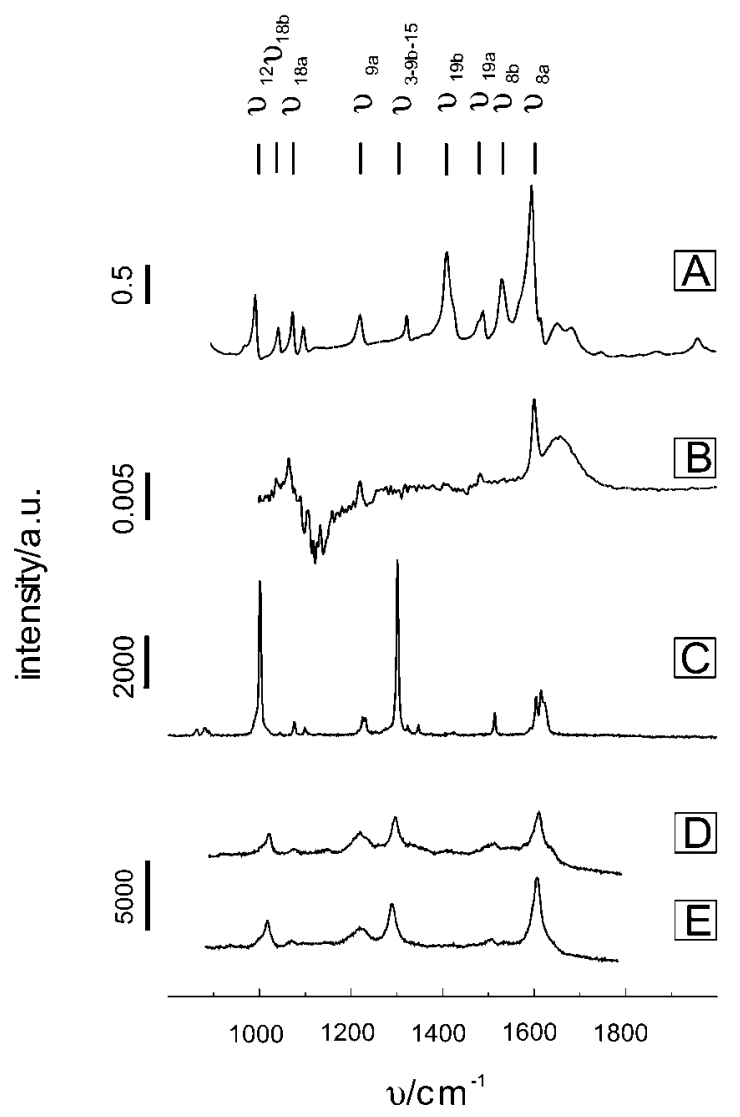

Figure 7. Comparison of IR and Raman spectra of 4,4'-BP: (A) IR spectrum of crystalline 4,4'-BP; (B) SEIRAS spectrum of $3 \mathrm{mM} \mathrm{4,4}-\mathrm{BP}$ in $0.05 \mathrm{M} \mathrm{KClO}_{4} / \mathrm{Au}(20 \mathrm{~nm}(111))$ at $0.20 \mathrm{~V}$; (C) Raman spectrum of crystalline 4,4'-BP $(\lambda=632 \mathrm{~nm}) ;(D, E)$

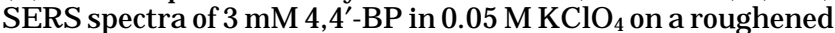
$\mathrm{Au}\left(\right.$ poly) electrode ${ }^{48}$ at 0.20 and $-0.60 \mathrm{~V}$.

4,4'-BP interacts weakly with $\mathrm{Au}(20 \mathrm{~nm})$ and does not change its optical properties upon adsorption.

\section{Discussion}

4.1. Molecular Orientation of 4,4'-BP in Region I. The free 4,4-BP molecule (crystalline, solution vapor phase) exhibits $D_{2 h}$ symmetry with 54 fundamental vibrational modes. The IR $\left(5 \mathrm{~B}_{1 \mathrm{u}}, 9 \mathrm{~B}_{2 \mathrm{u}}, 9 \mathrm{~B}_{3 \mathrm{u}}\right)$ and Raman modes $\left(10 A_{g}, 9 B_{1 g}, 5 B_{2 g}, 3 B_{3 g}\right)$, cf. definition of $x y z$ molecular axes as shown in Figure 4, are mutually exclusive. The four remaining $A_{u}$ modes are neither IR nor Raman active. The two pyridine rings contribute equally to the electronic and hence vibrational properties of the molecule. This situation changes if 4,4'-BP adsorbs on a metal surface $31-33,37-39,41$ and/or coordinates with metal ions. ${ }^{60}$ Monodentate substrate-adsorbate coordination via the nitrogen atom of one of the pyridine rings reduces the symmetry of the adsorbed 4,4'-BP from $D_{2 h}$ to $C_{2 v}$, which predicts identical IR and Raman modes (cf. pyridine, ${ }^{56,61} 2,2^{\prime}-B P,{ }^{57}$ or pyrazine ${ }^{58}$ ). The $D_{2 h}$ and $C_{2 v}$ fundamentals, referred tothecoordinatesystem in Figure 4, are related as follows: $B_{3 u}+A_{g} \rightarrow A_{1} ; B_{2 u}+B_{1 g} \rightarrow B_{2}$; $\mathrm{B}_{1 \mathrm{u}}+\mathrm{B}_{2 \mathrm{~g}} \rightarrow \mathrm{B}_{1} ; \mathrm{A}_{\mathrm{u}}+\mathrm{B}_{3 \mathrm{~g}} \rightarrow \mathrm{A}_{2}$.

The SEIRAS spectra in region I $(E>-0.100 \mathrm{~V}$ ) exhibit four bands of adsorbed 4,4'-BP $\left(v_{1065}\left(v_{18 a}\right)(\mathrm{W}), v_{1220}\left(v_{9 a}\right)\right.$ $(\mathrm{W}), v_{1484}\left(v_{19 a}\right)(\mathrm{W}), v_{1601}\left(v_{8 \mathrm{a}}\right)(\mathrm{s})$; Figure 3B, Figure 7B), which could be assigned to in-plane $\mathrm{B}_{3 u}$ modes. They represent changes of the mol ecular dipole moment al ong the $z$ axis (Figure 4). None of the $B_{2 u}$ vibrations (dipole changes along the in-plane y axis), rather strong in the crystalline phase or in solution $\left(v_{1411}\left(v_{19 \mathrm{~b}}\right), v_{1532}\left(v_{8 \mathrm{~b}}=\right.\right.$
Table 1. Characteristic Vibrational Modes of 4,4'-BPa

A. IR (crystal), in Situ SEIRAS, and SF G Experiments

\begin{tabular}{lccc}
\hline $\begin{array}{c}\text { mode } \\
\text { (symmetry) }\end{array}$ & $\begin{array}{c}\text { IR } v / \mathrm{cm}^{-1} \\
\text { bulk crystal }\end{array}$ & $\begin{array}{c}\text { SEIRAS } v / \mathrm{cm}^{-1} \\
\mathrm{Au}(20 \mathrm{~nm}) \mathrm{film}\end{array}$ & $\begin{array}{c}\mathrm{SFG} v / \mathrm{cm}^{-1} \\
\mathrm{Au}(111)\end{array}$ \\
\hline$v_{12}\left(\mathrm{~B}_{3 \mathrm{u}}\right)$ & 992 & & \\
$v_{18 \mathrm{~b}}\left(\mathrm{~B}_{2 \mathrm{u}}\right)$ & 1043 & & \\
$v_{18 \mathrm{a}}\left(\mathrm{B}_{3 \mathrm{u}}\right)$ & 1074 & 1065 & \\
$v_{9 \mathrm{a}}\left(\mathrm{B}_{3 \mathrm{u}}\right)$ & 1222 & 1220 & 1230 \\
$\Omega$ & & & 1295 \\
$v_{3-9 \mathrm{~b}-15}\left(\mathrm{~B}_{2 \mathrm{u}}\right)$ & 1323 & & $1345(?)$ \\
$v_{19 \mathrm{~b}}\left(\mathrm{~B}_{2 \mathrm{u}}\right)$ & 1411 & $1402^{*}$ & \\
$v_{19 \mathrm{a}}\left(\mathrm{B}_{3 \mathrm{u}}\right)$ & 1490 & 1484 & \\
$v_{8 \mathrm{~b}}\left(\mathrm{~B}_{2 \mathrm{u}}\right)$ & 1532 & $1527^{*}$ & \\
$v_{8 \mathrm{a}}\left(\mathrm{B}_{3 \mathrm{u}}\right)$ & 1598 & 1601 &
\end{tabular}

B. Raman and in Situ SERS Experiments

\begin{tabular}{clc}
\hline $\begin{array}{c}\text { mode } \\
\text { (symmetry) }\end{array}$ & $\begin{array}{c}\text { Raman } v / \mathrm{cm}^{-1} \\
\text { bulk crystal }\end{array}$ & $\begin{array}{c}\text { SERS }(0.20 \mathrm{~V}) v / \mathrm{cm}^{-1} \\
\text { Au(poly)/OxRed }\end{array}$ \\
\hline $\mathrm{A}_{g}$ & 1001 & 1017 \\
$\mathrm{~A}_{\mathrm{g}}(?)$ & 1076 & 1072 \\
$\mathrm{~A}_{\mathrm{g}}$ & 1231 & 1222 \\
$\mathrm{~A}_{\mathrm{g}}$ & 1302 & 1289 \\
$\mathrm{~B}_{1 \mathrm{~g}}$ & 1324 & \\
$\mathrm{~B}_{1 \mathrm{~g}}$ & 1428 & 1504 \\
$\mathrm{~A}_{\mathrm{g}}$ & 1514 & 1607 \\
$\mathrm{~A}_{\mathrm{g}}$ & $1606(1615)$ &
\end{tabular}

a TheSEIRAS modes marked by "asterisks" werefound in regions $I I, I I I$, and IV. TheSF G experiments have been limited totherange $1150 \mathrm{~cm}^{-1}<v<1450 \mathrm{~cm}^{-1}$. Characteristic individual spectra are plotted in Figure 7 and Figure 8.

1532); 60 Table 1, Figure 7A), was observed. In addition, the position of the ring stretching mode $v_{8 b}=1601 \mathrm{~cm}^{-1}$ $\left(B_{34}\right)$, which is sensitive to the interaction of the pyridine nitrogen with el ectron acceptors, ${ }^{60,62}$ shifts, in comparison to the response of the pure sol id sample, toward slightly higher wavenumbers (Table 1 ) indicating substrate adsorbate coordi nation. ${ }^{63}$ On the other hand, the small peak shift and the potential-independent background intensity suggest a rather weak interaction between 4,4'-BP and the positively charged gold surface. By application of the surface selection rule in SEIRAS that only normal components of the dipole change are IR active (cf. Introduction and refs 5 and 15), the preferential observation of $B_{3 u}$ modes in region I is interpreted such that 4,4'$\mathrm{BP}$ is adsorbed via one nitrogen atom in an end-on configuration with the $\mathrm{C}_{2}$ rotation axis of the molecule being perpendicular to the surface or with the $y$ axis parallel to the surface. No IR-forbidden modes, as for instance discussed in the case of pyrazine on rough gold surfaces, were found. 58,64 Flat-lying and edge-on configurations are clearly discarded. The frequency region bel ow $1000 \mathrm{~cm}^{-1}$, where out-of-plane modes occur, was not accessible in our IR experiments due to the cutoff of the silicon prism. Nevertheless, the tilted orientation can be excluded, based on in situ SERS experiments with polished $^{48}$ or roughened (oxidation/reduction cycles) ${ }^{38}$ polycrystalline gold el ectrodes (Figure 7D,E). No out-ofplane Raman modes, $B_{2 g}$, were found. The SER spectrum in region I is dominated by the symmetrical vibrational modes $A_{g}$ (Figure 7D,E), which correspond to a perpendicular end-on orientation of 4,4'-BP and strengthen the molecular packing model suggested from the STM experiments ${ }^{31}$ (Figure 9). These spectral features are similar to those observed on silver electrodes. ${ }^{32,33}$ Except for theinterring stretching mode $v_{1289}(\Omega)$ and for the ring mode $v_{1021}$

(62) Barker, D. J .; Buchleton, J . S.; Clark, G. R.; Cooney, R. P.; Richard, C. E. F. J. Mol. Struct. 1990, 239, 249.

(63) Metiu, H. Prog. Surf. Sci. 1984, 17, 153.

(64) Brolo, A.; Irish, D. E. J . Electroanal. Chem. 1996, 414, 188. 


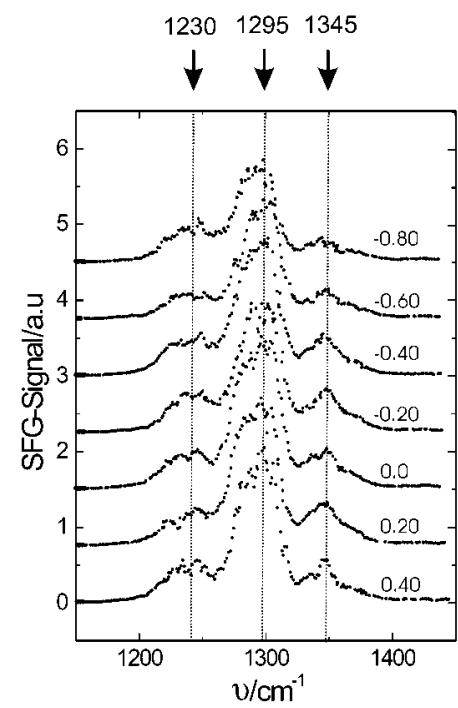

Figure 8. Sel ected potential-dependent SF G spectra of $3 \mathrm{mM}$ $4,4^{\prime}-\mathrm{BP}$ in $0.05 \mathrm{M} \mathrm{KClO}_{4}$ on $\mathrm{Au}(111) .49$

$\left(v_{12}\right)$ all SERS-active Ag vibrations exhibit counterparts of $\mathrm{B}_{34}$ symmetry at rather similar wavenumbers in the SEIRA spectrum. This coincidence of SER and SEIRA spectra supports the symmetry reduction toward $\mathrm{C}_{2 \mathrm{v}}$ implying that all vibrational modes become Ramanallowed (cf. pyrazine in ref 58). Despite the fact that the inter-ring stretching mode $\Omega \sim 1289 \mathrm{~cm}^{-1}$ is not found in the SEIRA spectrum, we can conclude from the existence of a distinct resonance feature around $1295 \mathrm{~cm}^{-1}$, as reported in a recent visible-infrared in situ SFG experiment $^{49}$ (F igure 8), that this mode is indeed I $R$ active for adsorbed 4,4'-BP on Au(111) in region I. Other SF G-active resonances in the range $1150 \mathrm{~cm}^{-1}<v<1450 \mathrm{~cm}^{-1}$ were found around $1230 \mathrm{~cm}^{-1}\left(v_{9 a}\right)$ and $1345 \mathrm{~cm}^{-1}$. Theintensity decreases with more negative potential while the peak position remains rather constant. The nature of $v_{1345}$ is not yet clear. ${ }^{49}$ We recall that the detection of a SFG resonance requires as a necessary condition its simultaneous IR and Raman activity. ${ }^{3}$

4.2. Orientation of 4,4'BP in Regions II, II, and IV. (1) The increasing loss intensity of all SEIRAS-active $\mathrm{B}_{3 u}$ modes (Figures 5 and 6 ), (2) the simultaneous occurrence of two new in-plane $\mathrm{B}_{2 \mathrm{u}}$ vibrations, $v_{1405}\left(v_{19 \mathrm{~b}}\right)$ $(\mathrm{m}), v_{1527}\left(v_{8 \mathrm{~b}}\right)(\mathrm{w})$, with the latter having also a weak counterpart in the SER spectrum, ${ }^{48}$ and (3) the absence of out-of-plane $B_{2 g}$ SERS modes at $v<1000 \mathrm{~cm}^{-1}$ demonstrate that the partial desorption of 4,4'-BP at $E<$ $\mathrm{P} 1$ is accompanied by an in-plane tilt of the remaining surface-bound organic molecules in the yz plane. The $\mathrm{N}$ coordination between 4,4'-BP and the gold surface and the dominant lateral interactions between the adsorbed molecules ( $\pi$ stacking) seem to remain unchanged, as indicated by the potential dependence of the positions of the respective vibrational modes and of the baseline intensity. The exact tilt angle could not be determined. The potential dependence of themost prominent stretching band $v_{1601}\left(v_{8 a}\right)$ suggests two possible "tilt steps", which could be associated with the adlayers II and III. Both structures have been characterized in high-resolution in situ STM experiments ${ }^{31}$ (Figure 9B,C). The decrease of the Raman intensity of the symmetrical $A_{g}$ modes with more negative electrode potentials correlates with this inter petation (Figure 6A). In addition, one may conclude from the existence of these modes at potential s even more negative than $-0.600 \mathrm{~V}$ (Figure 7D, Figure 8) that the reduction of $4,4^{\prime}-\mathrm{BP}$ past $\mathrm{P} 3$ occurs not in a completely flat but rather in slightly tilted orientation with reduction products remaining partially adsorbed on thesurface. ${ }^{32,33,48}$

4.3. Comparison with Other N-Heterocyclic Molecules and Role of Coadsorbed Water. Macroscopic and molecular monolayer model $s^{65,66}$ represent the adsorption of solute (A) and solvent molecules at metal/ aqueous el ectrolyteinterfaces by equations of thefollowing type ${ }^{67}$

$$
\mathrm{A}_{\text {bulk }}+\mathrm{nH}_{2} \mathrm{O}_{\text {ads }} \leftrightarrow \mathrm{A}_{\text {ads }}^{\lambda}+\mathrm{nH}_{2} \mathrm{O}_{\text {bulk }}+\lambda \mathrm{e}^{-}
$$

$\lambda \mathrm{e}^{-}$represents the transfer of $\lambda$ electrons.

Combined thermodynamic (chronocoulometry) and structure-sensitive studies with well-defined electrodes demonstrated that the adsorption of organic molecules is influenced by the properties of interfacial water ("hydrophobic effect" 68,69 ), ions of the supporting electrolyte, structural properties of the solute (hydrogen bonding, $\pi$ stacking, substrate-adsorbate coordination, ion pairing, ...), and thesubstratesurface (crystallographicorientation, material). ${ }^{70,71}$ Theadsorption of monofunctional aliphatic compounds on gold surfaces has the character of weak physisorption, which is dominated by $\mathrm{Au}-\mathrm{H}_{2} \mathrm{O}, \mathrm{A}-\mathrm{H}_{2} \mathrm{O}$, and $\mathrm{H}_{2} \mathrm{O}-\mathrm{H}_{2} \mathrm{O}$ interactions (hydrophobic expulsion ${ }^{68}$ ) modified by the interfacial el ectric field. ${ }^{72,66}$ On the other hand, adsorption between aromatic nitrogen-containing heterocyclic molecules and a gold electrode has the character of weak chemisorption (metal-ligand interaction), which involves predominantly either (1) interactions between the $\pi$ electrons of the aromatic ring and the delocalized, polarizable free electrons in the metal or (2) a mixing of the $\mathrm{N}$-lone pair orbitals with the electronic states of the metal. ${ }^{70}$ Depending on the applied electrode potential, the heterocyclic adsorbate may assume both (1) a $\pi$-bonded or flat-lying position with the aromatic ring parallel to the negatively charged surface and (2) $\mathrm{N}$-bonded (vertical, tilted, and/or rotated) orientations. In the following we will discuss our results of 4,4'-BP in comparison to the interfacial properties of other $\mathrm{N}$ heter ocyclicmolecules adsorbed on massiveor thin, quasisingle crystalline gold electrodes.

Flat orientations, in which the aromatic rings of the molecule are oriented parallel to the electrode surface, was reported for pyridine (Py), ${ }^{73,56}$ pyrazine (pz), ${ }^{74,75}$ and 2,2'-bipyridine (2,2'-BP $)^{76,77,78}$ based on chronocoul ometry, in situ STM, and ex situ XPS studies. In situ SEIRAS

(65) Damaskin, B. B.; Petrii, O. A.; Batrakov, V. V. Adsorption organischer Verbindungen an Elektroden; Akademie-Verlag: Berlin, 1975.

(66) Cf. reviews in: Adsorption of Molecules at Metal Electrodes; Lipkowski, J ., Ross, P. N., Eds.; VCH: New York, 1992.

(67) Koppitz, F. D.; Schultze, J . W.; Rolle, R. D. J . Electroanal . Chem. 1984, 170, 5 .

(68) I sraelachvili, J . Intermol ecular and Surface F orces; Academic Press: London, 1992.

(69) Tabor, D. J . Colloid Interface Sci. 1977, 58, 2.

(70) Lipkowski, J .; Stol berg, L.; Yang, D. F.; Pettinger, B.; Mirwald S.; Henglein, F.; Kolb, D. M. Electrochim. Acta 1994, 39, 1045.

(71) Interfacial Electrochemistry; Wieckowski, A., Ed.; M. Dekker, Inc.: New York, 1999.

(72) Beltowska-Brzezinska, M.; Luszak, T.; Holze, R. Surf. Sci. 1998 418, 281.

(73) Stol berg, L.; Morin, S.; Lipkowski, J .; I rish, D. E. J . Electroanal. Chem. 1991, 307, 241.

(74) I anelli, A.; Merza, J .; Lipkowski, J .J . Electroanal. Chem. 1994 $376,49$.

(75) Hamm, U.; Lazarescu, V.; Kolb, D. M. J . Chem. Soc., Faraday Trans. 1996, 92, 3785.

(76) Yang, D. F.; Bizzotto, D.; Lipkowski, J .; Pettinger, B.; Mirwald, S. J. Phys. Chem. 1994, 98, 7083.

(77) Cunha, F.; Tao, N. J . Phys. Rev. Lett. 1995, 75, 2376.

(78) Dretschkow, Th.; Lampner, D.; Wandlowski, Th. J . Electroanal. Chem. 1998, 458, 121. 


\section{adlayer I}
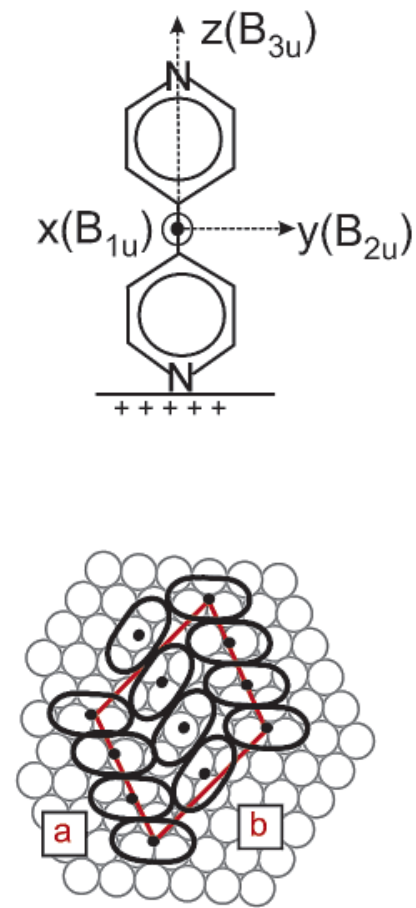

\section{adlayer II}
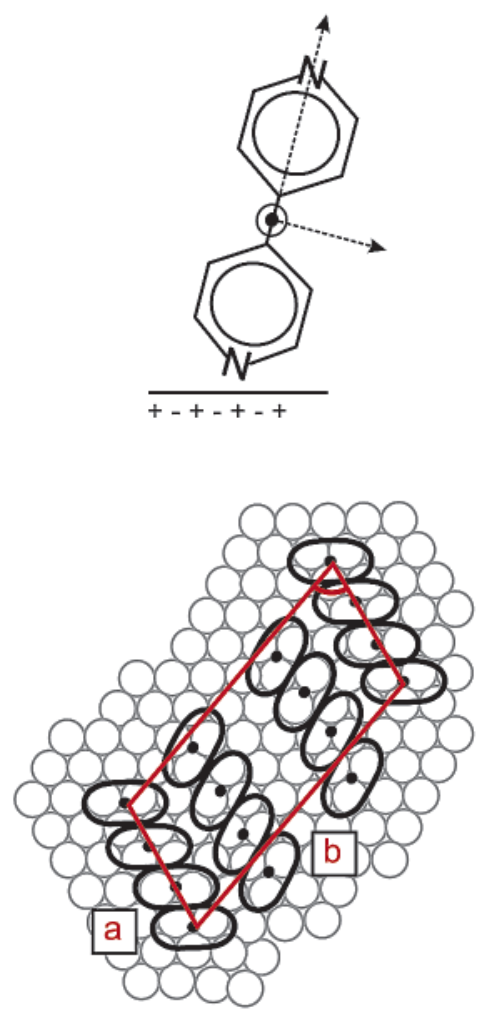

\section{adlayer III}
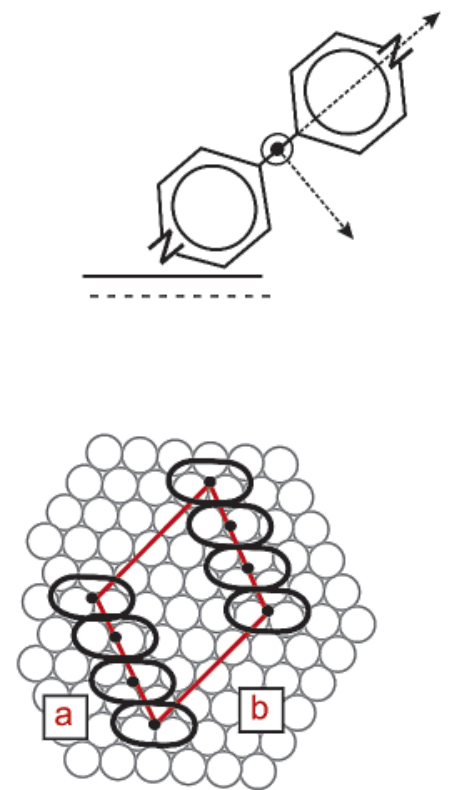

Figure 9. Orientation (derived from SEIRAS experiments) and packing (STM ${ }^{31}$ ) models of 4,4'-BP on Au(111).

experiments, ${ }^{56,58,79}$ which only probe the Helmholtz and Gouy regions, revealed that theformation of the $\pi$-bonded adsorption state of all three molecules is accompanied by the replacement of water molecules from the electrode surface, in accord with the model expressed by eq 2. Detailed analysis of the bending mode of water, $\delta_{\mathrm{HOH}}$, as reported for pyridine, ${ }^{56}$ showed that the loss features consists of two components representing individual and hydrogen-bonded water molecules. Upon changing the electrode potential, all three heterocyclic molecules coordinate to the positively charged surface with one (Py, $\mathrm{Pz}$ ) or, in a coplanar cis-configuration, with both nitrogen atoms (2,2'-BP). This type of adsorbate-substrate coordination reduces the molecular symmetry to $C_{2 v}$, and as a consequence all vibrational modes become Raman active. ${ }^{58,79}$ Comparable SERS, IRAS, SEIRAS, and SFG investigations showed that the high coverage phase of Py represents a slightly rotated and end-on configuration, ${ }^{56,61,80}$ while $\mathrm{Pz}$ and 2,2'-BP are both vertically oriented. 58,79,81 These coordinated adsorption states are stabilized by attractive, lateral $\pi$-stacking interactions between adjacent aromatic rings giving rise to twodimensional ordered monolayers. Typical contrast pattern of in situ STM experiments revealed large domains of parallel molecular stacking rows separated by $0.9-1.5$ $\mathrm{nm}$ with intermolecular distances of $0.38-0.45 \mathrm{~nm}$ and molecules tilted up to $30^{\circ}$ from the normal of the chain

(79) Noda, H.; Minoha, T.; Wan, L. J .; Osawa, M. J . Electroanal. Chem. 2000, 481, 62.

(80) Hebert, P.; Le Rille, A.; Zheng, W. Q.; Tadjeddine, A. J . Electroanal. Chem. 1998, 447, 5 .

(81) Hoon-Khosla, M.; F awcett, W. R.; Goddard, J . D.; Tian, W. Q.; Lipkowski, J . Langmuir 2000, 16, 2356. axis. ${ }^{56,77,78,82}$ Py and 2,2'-BP form thesamestacking pattern in neutral and in acidic solutions, e.g., under conditions where at least one nitrogen atom is protonated in the bulk phase. ${ }^{56,77-79}$ This result reflects the strength of the chemisorbed adlayer. Similar cl ose-packed N-coordi nated 2D stacking structures were also reported for $1,10^{\prime}$ phenanthroline (Phen) ${ }^{83}$ and 2,2'-6,2' '-terpyridi ne (TP) ${ }^{84}$ on $\mathrm{Au}$ (111). All fivemolecules are coordinated tothemetal surface through the nitrogen heteroatom and with the phenyl ring(s) di rected toward the bulk electrolyte, which causes the hydrophobic hydration ${ }^{68,85}$ of the organic adlayer, accompanied with the displacement of surface water according to eq 2. This, mainly entropic phenomenon arises from the structural rearrangement of water molecules in the overlapping solvation zones as two (or more) organic adspecies approach each other. ${ }^{68}$ SEIRA spectra of $\mathrm{Py}, \mathrm{Pz}$, and 2,2'-BP indeed show pronounced water loss features in the $\mathrm{OH}$ bending $\left(\delta_{\mathrm{HOH}}\right)$ and the $\mathrm{OH}$ stretching $\left(\nu_{\mathrm{OH}}\right)$ regions with increasing adsorbate coverage. ${ }^{56,58,79}$ One also notices that the $\mathrm{N}$-bonded adsor ption causes (1) a shift of the prominent symmetric $A_{1}$ molecular ring modes (in $\mathrm{C}_{2 v}$ symmetry) toward higher wavenumbers, compared to the corresponding vibrations of the free mol ecule, and (2) an increase in the baseline level of the spectra. The latter represents the background reflectivity of the electrode or, in other words, the optical properties of the metal. ${ }^{86,87}$ Both trends are more pronounced with

(82) Andreasen, G.; Vela, M. E.; Salvarezza, R. C.; Arvia, A. J . Langmuir 1997, 13, 6814.

(83) Cunha, F.; in, Q.; Tao, N.J .; Li, C. Z. Surf. Sci. 1997, 389, 19.

(84) Pinheiro, L. S.; Temperini, M. L. A. Surf. Sci. 2000, 464, 176.

(85) Conway, B. E.; Mathieson, J . G.; Dhar, H. P. J . Phys. Chem. 1974, 78, 1226.

(86) Ataka, K.; Osawa, M. J . Electroanal. Chem. 1999, 460, 188. 
increasing strength of chemisorption of the adsorbate (Pz $<$ Py $<2,2^{\prime}-B^{56,58,79}$ ).

Theadsorption of 4,4'-BP on $\mathrm{Au}(111)$ reveal s somesubtle differences, in comparison to $\mathrm{Py}, \mathrm{Pz}, 2,2^{\prime}-\mathrm{BP}$, Phen, and TP: The formation of the anion radical prevented an unambiguous conclusion on a possible flat orientation of $4,4^{\prime}-\mathrm{BP}$ at sufficiently negative potentials in the low coverageregion. ${ }^{31,38}$ At E $>-0.500$, e.g., still at a negatively charged electrode, a first in-plane tilted N-coordinated adlayer is formed, which transforms intoa densely packed, interdigitated stacking pattern of all-perpendicularly arranged 4,4'-BP molecules at a positively charged Au(111) surfacein two discretesteps ${ }^{31}$ (Figure9). Thesurface coordination is rather weak, as indicated by (1) the small upshift of the $A_{1}$ ring frequencies in $C_{2 v}$ geometry and (2) the potential independence of thebaselinelevel (Table 1). The absolute SEIRA spectra reveal (cf. Figure 3) that the increase of the 4,4'-BP coverage is accompanied by an increase of oriented interfacial water, as compared with the adsorbate-free reference. The narrower bandwidth, $\sim 214 \mathrm{~cm}^{-1}$, of the $\mathrm{OH}$ stretching contribution for strong hydrogen bonding, $v_{\mathrm{OH}}\left(3484 \mathrm{~cm}^{-1}\right)$, and of the bending mode, $\delta_{\mathrm{HOH}}$ at $1650 \mathrm{~cm}^{-1}$ with $87 \mathrm{~cm}^{-1}$ (fwhm), compared to bulk water $\left(400 \mathrm{~cm}^{-1}\right.$ at $3370 \mathrm{~cm}^{-1}$ and $100 \mathrm{~cm}^{-1}$ at $1648 \mathrm{~cm}^{-1}$ ) suggest an ordered water structure surrounding the 4,4'-BP monolayer. The second nitrogen, which faces the electrolyte, can directly participate in hydrogen bonding to the adjacent solvent molecules. This configuration is valid in all three potential regions of $\mathrm{N}$ coordinated 4,4'-BP. The hydrophilic adsorption, e.g., the co-deposition of densely packed 4,4'-BP and (at least) second-layer ordered water molecules is supported by (1) EQCM experiments, where Wilde et al . could not find any mass changes upon 4,4'-BP adsorption on gold film electrodes ${ }^{35}$ as well as (2) by the high sensitivity of the STM contrast pattern of 4,4'-BP in the $\mathrm{N}$-coordinated phases to tunneling currents larger than 30 pA. (Steadystate imaging requires unusually large distances between sample and tip!) ${ }^{31}$ The classical picture, "substitution of solvent molecules by adsorbed organic species", as represented by eq 2 is not valid. Remarkable structural changes of the electrolyte may occur within the entire interfacial region of density inhomogeneities (usually only two, at most threelayers ${ }^{88}$ ) that parallel the formation of hydrophilic organic monolayers. The unique sensitivity

(87) Futamata, M. Chem. Phys. Lett. 2001, 333, 337. and selectivity, and its exclusive penetration depth into the Helmholtz and Gouy regions, ${ }^{5}$ qualify SEIRAS as an ideal approach to explore these phenomena in detail. Futamata et al. ${ }^{37}$ reported, for instance, in an ATR-IR study that diprotonated $4,4^{\prime}-\mathrm{BPH}_{2}{ }^{2+}$ adsorbs only in perchl orate containing electrolyte in direct contact with the gold surface, while more strongly adsorbed $\mathrm{SO}_{4}{ }^{2-}$ or $\mathrm{Cl}^{-}$ions expel 4,4'- $\mathrm{BPH}_{2}{ }^{2+}$ into the second layer outside the contact-adsorbed anions. The adsorbate-induced coformation of ordered water in the electrochemical double layer region of $\mathrm{Au}(111) / e l$ ectrolyte interfaces was also observed for $\mathrm{Cu}$ underpotential deposition (UPD) in $\mathrm{H}_{2-}$ $\mathrm{SO}_{4}{ }^{87}$ (but not for $\mathrm{Pb}$ UPD neither in $\mathrm{H}_{2} \mathrm{SO}_{4}$ nor in $\mathrm{HClO}_{4}$ duetothe completedischargeof the $\mathrm{Pb}^{2+}$ !), the deposition of fumaricacid, ${ }^{89}$ and 4-mercaptopyridine. ${ }^{90}$ The common features of all thesesystems arehydrophilicgroups $\mathrm{SO}_{4}{ }^{2-}$, $\left.-\mathrm{COO}^{-},\right\rangle \mathrm{N} \mid$ ) exposed tothe el ectrolyte. We speculate (due tothecurrent lack of experimental data) that many organic spacers with functional groups that act as "bait" to promote surface binding and operation of protei ns likecytochrome c, such as carboxylates, sulfonates, phosphates or 4-pyridyl, and aniline-type amines, $\mathrm{ArN}_{2}{ }^{21}$ undergo hydrophilic adsorption on gold surfaces and induce a high order of interfacial water. If thehydrophilic groups are blocked, for instance, by surface coordination as in the case of cytosine $^{86}$ or uracil ${ }^{91}$ on $\mathrm{Au}(111)$, classical hydrophobic adsorption and phase formation are observed. SEIRAS appears to be a valuable tool to devel op these structural concepts further.

Acknowledgment. The present work was supported by the Volkswagen Foundation (77/116), theEG through IC-014-00, and the Research Center J ülich. K.A. is indebted to the Alexander von $\mathrm{H}$ umbol dt $\mathrm{F}$ oundation for a Research Fellowship. Theauthors alsoacknowledgethe support of Professor Ibach, the stimulating discussions with Professor Z. Q. Tian, Professor A. Tadjeddine, and Dr. D. Diesing, and technical assistance of J . I konomov.

\section{LA025585K}

(88) Spohr, E. Habilitation, University of UIm, 1995

(89) Noda, H.; Ataka, K.; Wan, L. J .; Osawa, M. Surf. Sci. 1999 427-428, 190

(90) Hara, Y.; Wan, L. J .; Noda, H.; Taniguchi, I.; Osawa, M. J . Electroanal. Chem., in press.

(91) Pronkin, S.; Wandlowski, Th. In preparation. 